\title{
Medscape Oncology
}

Management of Polycythemia Vera: Virtual Simulation Improves Clinical Decisions of Hematologists/Oncologists

LAUREN WILLIS, PHARMD, BCOP; RICH CARACIO, MBA; MARTIN WARTERS, MA, CHSE; GWEN LITTMAN, MD, Medscape, LLC, New York, NY

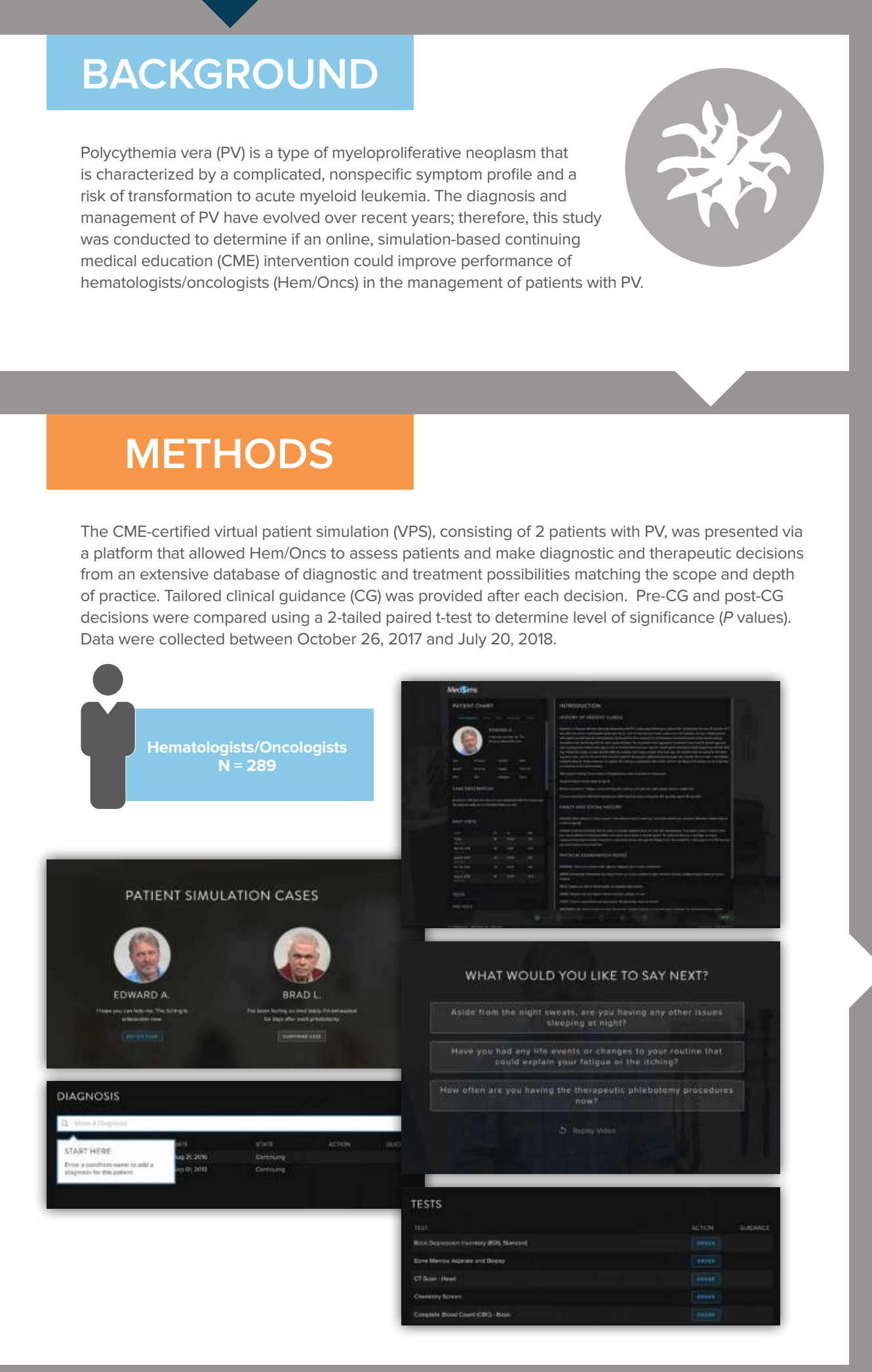

\section{RESULTS}

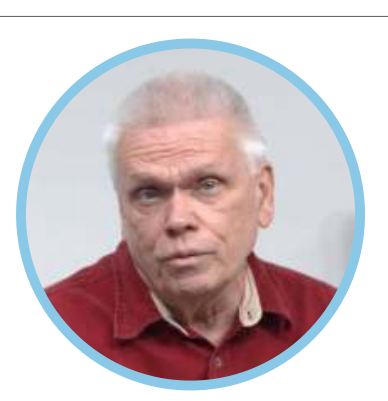

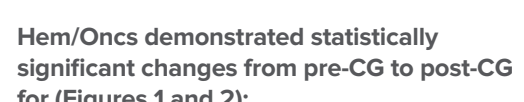

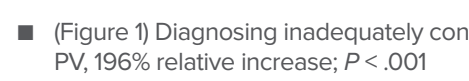

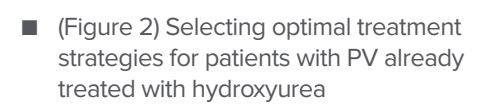

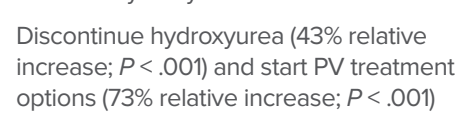

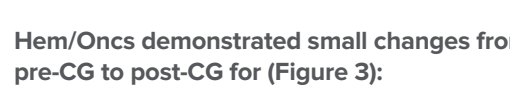
- Assessing symptom burdeni in patiens

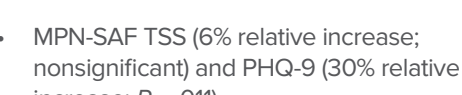

Tatment Selection: Ruxolitinib Figure a

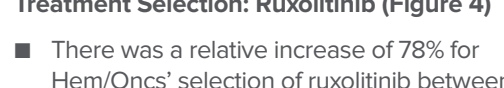

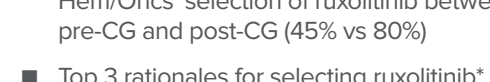

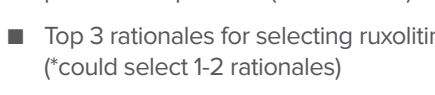

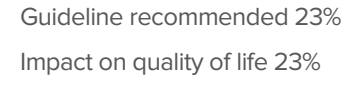

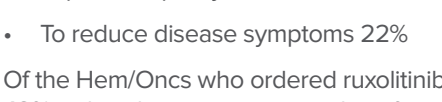

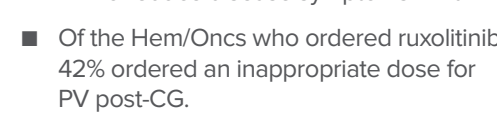
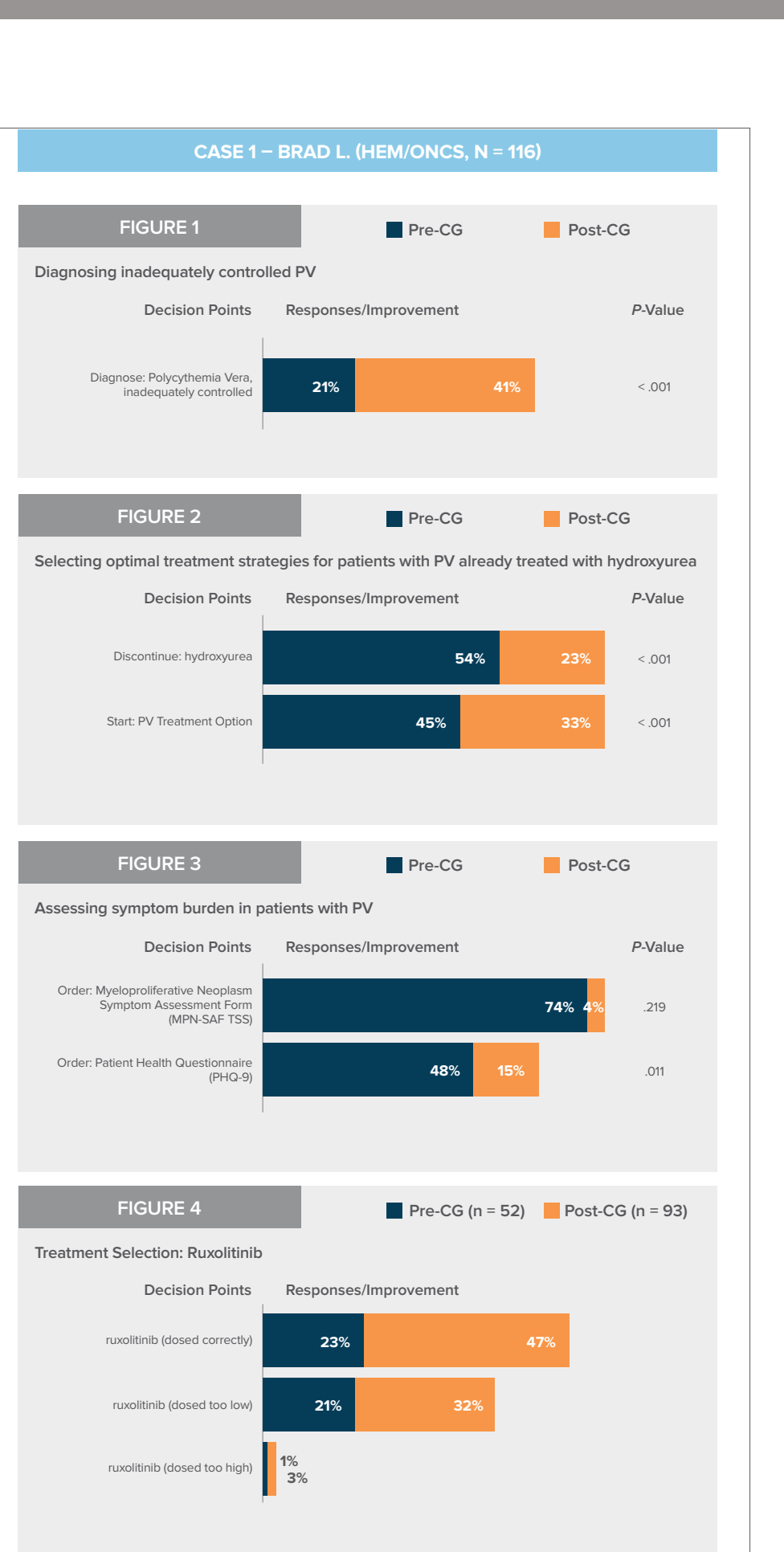

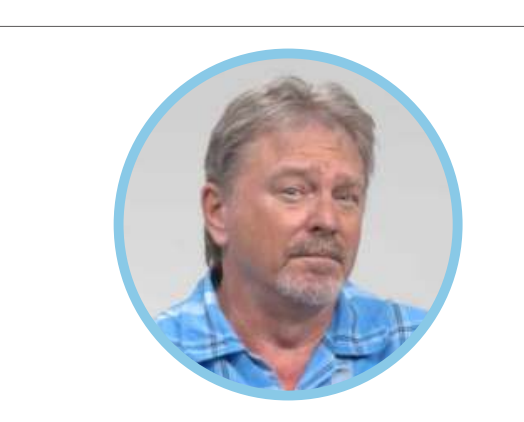

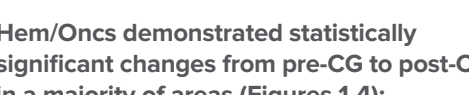

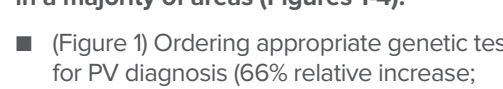

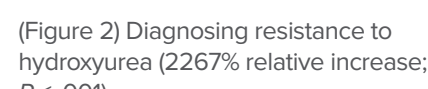

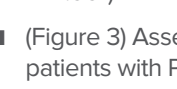

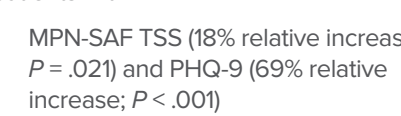

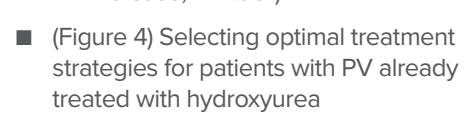

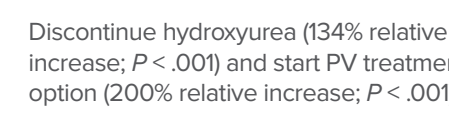

Treatment Selection: Ruxolitinib (Figure 5 )

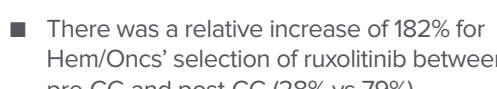

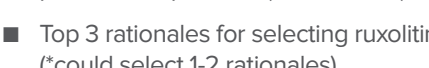

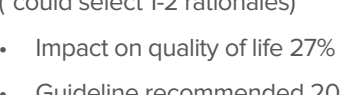

- Tudeline recorminended $20 \%$

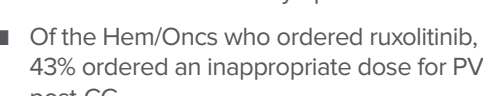

CONCLUSION

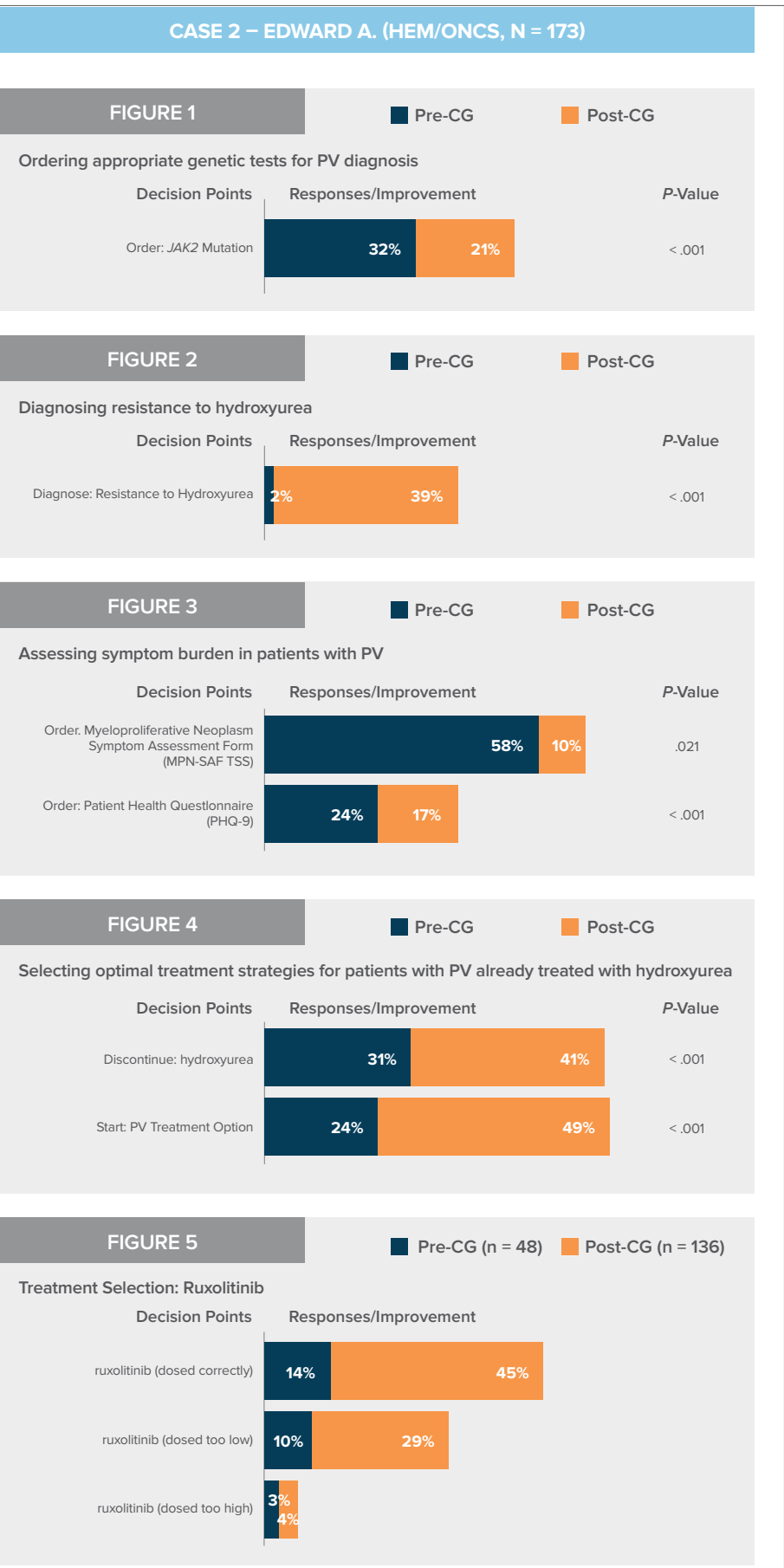

This study demonostrates that ves hin

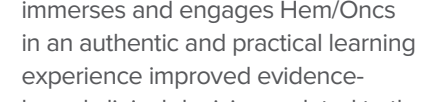

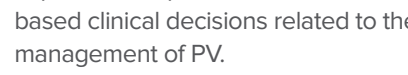

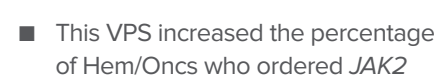

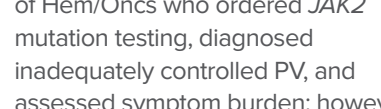

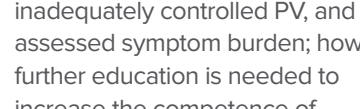

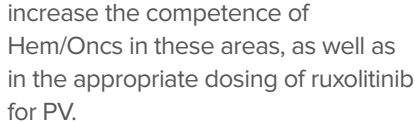

ACKNOWLEDGMENTS

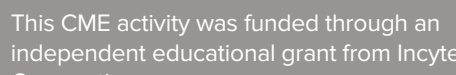

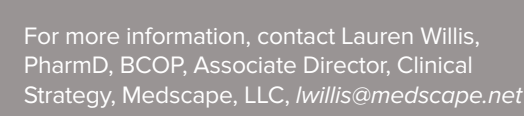

